\title{
JANE FRANCES ELGEE \& OSCAR WILDE UMA TEORIA DOS AFETOS
}

Patricia Gonçalves Tenório é escritora de poemas, contos e romances desde 2004, tem 8 livros publicados e é mestranda em Teoria da Literatura pela Universidade Federal de Pernambuco, linha de pesquisa Intersemiose, com o projeto "O retrato de Dorian Gray, de Oscar Wilde: um romance indicial, agostiniano e prefigural", sob a orientação de Prof. Dra. Maria do Carmo de Siqueira Nino. Contatos: www.patriciatenorio.com.br e patriciatenorio@uol.com.br

\begin{abstract}
Resumo
$\mathrm{O}$ presente artigo pretende investigar o caso de paralisia do escritor irlandês Oscar Wilde diante do pedido de sua mãe Jane Frances Elgee no momento do processo que o levou à prisão por homossexualidade com a utilização de trechos de seu único romance, $\mathbf{O}$ retrato de Dorian Gray, à luz dos conceitos de Narcisimo e Complexo de Édipo (esse último especialmente no estudo "Os arruinados pelo êxito") do pai da psicanálise Sigmund Freud.
\end{abstract}

\begin{abstract}
This article intends to investigate the case of paralysis of the Irish writer Oscar Wilde on the request of his mother Jane Frances Elgee at the moment of the process that led him to prison for homosexuality with the use of excerpts from his only novel, The Picture of Dorian Gray, according to the concepts of Narcissism and Oedipus Complex (the latter especially in the study "The Spoiled by Success") of the psychoanalysis's father Sigmund Freud.
\end{abstract}

Todas as mulheres chegam a parecer-se com suas mães. É a tragédia delas.

Os homens não. É a tragédia deles.

A importância de ser Prudente, Oscar Wilde

\section{1) Quando tudo se desfaz: Um pacto (auto)biográfico}

Imaginemos a seguinte cena descrita pelo poeta William Butler Yeats no Cadogan Hotel em Londres. Lady Wilde entra no quarto de Oscar Wilde, nas últimas horas de liberdade de seu filho e fala:

- "Se ficar, ainda que seja mandado para a prisão, você permanecerá meu filho. Isso não mudará em nada a afeição que sempre tive por você. Mas se partir, eu nunca mais lhe dirigirei a palavra" (YEATS in SCHIFFER, 2010, p. 218).

Estamos no ano de 1895. Oscar Wilde, escritor, dramaturgo, poeta, crítico de arte nascido na Irlanda e de país adotivo a Inglaterra, aclamado na Europa e na América, é acusado de sodomia pelo Marquês de Queensberry, pai de Lorde Alfred Douglas, quase vinte anos mais jovem, com quem - apesar de não admitir nem para seus advogados - mantinha um relacionamento amoroso. Em uma das maiores reviravoltas da história jurídica mundial, Oscar Wilde, coagido por seu amante, acusa o Marquês de assédio moral e este consegue reverter o processo a seu favor, condenando o escritor irlandês a dois anos de prisão com trabalhos forçados.

Por que teria Oscar Wilde cedido ao pedido de sua mãe de não fugir quando teve oportunidade, sem ouvir aos apelos de seus amigos, entre eles Robert Ross, primeiro 
amante, amigo fiel até a morte e herdeiro universal da obra de Wilde? Para tentarmos compreender melhor, voltemos quarenta e um anos no tempo.

Oscar Fingal O'Flahertie Wills Wilde nasceu no dia 16 de Outubro de 1854 em Dublin, Irlanda, na Westland Row, número 21, segundo filho do casal burguês-irlandêsprotestante William Robert Wilde e Jane Frances Elgee. Seu pai era especialista em doenças dos olhos e ouvidos, e graças a seus vastos conhecimentos médicos, veio a tornar-se o cirurgião-oculista da rainha Vitória, recebendo por isso o título de "Sir". Homem de múltiplos talentos, escreveu o Catalogue of The Antiquities in The Museum of The Royal Irish Academy, em que narra a história celta, e o Irish Popular Superstitions, sobre o folclore irlandês.

Jane Frances Elgee, a futura Lady Wilde, era uma mulher de personalidade forte, megalomaníaca e esnobe. A começar pela troca do segundo nome de "Frances" para "Francesca", apesar de não possuir nenhuma descendência italiana. Nacionalista fervorosa e amante das artes, reunia em sua residência artistas das mais altas e também das mais baixas qualidades e categorias, entre os primeiros, George Bernard Shaw e William Butler Yeats, ambos futuros Prêmio Nobel em Literatura.

Lady Wilde era poetisa revolucionária e tinha seus poemas publicados por Charles Gavan Duffy, redator-chefe da The Nation - revista político-literária que defendia a independência da Irlanda. Quando Duffy foi preso por suspeita de atividades secessionistas, Lady Wilde, num de seus rompantes, escreve e publica anonimamente na revista dois artigos inflamando o início da guerra contra a Inglaterra. Apesar de preso, Charles foi tomado como o responsável pelos artigos, e Lady Wilde, mais por vaidade por não ter sido reconhecida que por heró́smo, recorreu ao procurador da Coroa para assumir a autoria dos textos panfletários e ainda conseguiu absolver o senhor Duffy.

Mesmo com sua incontestável altivez, Lady Wilde aparentemente nunca se realizou como poetisa. Teve três filhos com Sir William: William, o primogênito, praticamente com o mesmo nome do pai (apenas o Kingsbury o diferenciava), Oscar, que muito se assemelhava à mãe, tanto fisicamente - Lady Wilde media 1,80 m de altura, e Oscar, quase 1,90 m - quanto na personalidade, e Isola, que faleceu aos nove anos, vítima de uma febre mal cuidada - fato que abalou enormemente tanto à mãe, quanto a Oscar, muito apegado à irmã caçula.

Apesar da grande maioria dos textos serem ficção, marcas autobiográficas estão continuamente presentes em toda a obra de Oscar Wilde, em especial no seu único romance $O$ retrato de Dorian Gray, nos trechos em que o escritor trata da família. Feito classifica diversos teóricos, entre eles Philippe Lejeune em O pacto autobiográfico:

Esses textos entrariam na categoria do "romance autobiográfico". Chamo assim todos os textos de ficção em que o leitor pode ter razões de suspeitar, a partir das semelhanças que acredita ver, que haja identidade entre autor e personagem, mas que o autor 
escolheu negar essa identidade ou, pelo menos, não afirmá-la. Assim definido, o romance autobiográfico engloba tanto narrativas em primeira pessoa (identidade do narrador e do personagem) quanto narrativas "impessoais" (personagens designados em terceira pessoa); ele se define por seu conteúdo. À diferença da autobiografia, ele comporta graus. A "semelhança" suposta pelo leitor pode variar de um vago "ar de família" entre o personagem e o autor até uma quase transparência que leva a dizer que aquele é o autor "cuspido e escarrado". (LEJEUNE, 2008, p. 25)

\section{2) Quando a vida encontra a arte: Oscar Fingal O'Flahertie Wills Wilde}

São várias as passagens em $O$ retrato de Dorian Gray em que Wilde coloca na boca de seus personagens a relação afetiva com sua família. Vejamos o caso de seu irmão mais velho William.

William Robert Kingsbury Wilde, mais conhecido como Willie, não era um homem atraente, muito menos teve uma vida de sucesso feito seu irmão. Alcóolatra, chegou a escrever uma crítica anônima à Vanity Fair contra a primeira peça de sucesso de Oscar, "O leque de Lady Windermere". Em uma das passagens de $O$ retrato, o irônico e hedonista Lorde Henry, um dos alter-egos de Wilde no romance, dispara a seguinte frase:

- “Ah, irmãos! Os irmãos não me interessam. Meu irmão mais velho se recusa a morrer, e os mais moços não parecem fazer outra coisa" (WILDE, 2013, p. 89).

Ou mesmo em outra passagem mais adiante:

- "Meu caro, não estou falando totalmente a sério. Mas não posso deixar de detestar meus parentes. Creio que isso se deve ao fato de que não conseguimos tolerar outras pessoas que tenham o mesmo defeito que nós" (WILDE, 2013, p. 89).

Encontramos Oscar Wilde em várias obras suas mimetizando a própria mãe. $\mathrm{Na}$ primeira peça teatral, "Vera ou os Niilistas", essa mulher forte e revolucionária que Wilde via em Lady Wilde é um ser capaz de "Estrangular até o derradeiro resquício de natureza que há em mim; não amar, nem ser amado; não conceder, nem implorar piedade (...)" (WILDE, 2007, p. 460), mas que o filho redime sempre ao final do texto, sempre ao final da história, feito para tentar lhe perdoar.

"A Duquesa de Pádua" repete a mulher revolucionária casada com o Duque de Pádua que declama a mesma frase do pai de "Vera ou os Niilistas" demonstrando com isso a falta de interesse e solidariedade pelos demais.

“- Não fui eu que fiz o mundo” (WILDE, 2007, p. 516).

Notamos nesses dois textos indícios para $O$ retrato de Dorian Gray. Em "Vera", na conversa entre o príncipe Paulo Maraloffski e o filho do Czar, disfarçado no meio dos niilistas como Aleixo Ivanacievitch, aquele declara o mesmo pensamento de lorde Henry Wottom em relação aos amigos. 
“- Na verdade, preferia perder meu melhor amigo a perder meu pior inimigo. Para ter-se amigos, como sabeis, basta ser de bom natural; mas quando a um homem não resta inimigo, deve haver nele algo de mesquinho" (WILDE, 2007, p. 474).

Enquanto isso em $O$ retrato de Dorian Gray, lorde Henry declara:

- Que injustiça a sua! (...) Diferencio perfeitamente as pessoas. Escolho os amigos por sua boa aparência, os conhecidos por seu caráter e os inimigos por seu intelecto. Um homem precisa saber escolher bem seus inimigos. Não tenho nenhum que seja idiota. Como são homens com algum poder intelectual, todos me apreciam. (WILDE, 2013, p. 89)

Mas era uma relação de ambuiguidade a que Oscar Wilde mantinha com seu pai, Sir William, mais de respeito que de afeição. Um dos motivos parece ser um escândalo sofrido por seu pai (e consequentemente por toda a sua família) quando Oscar ainda não havia completado dez anos, escândalo que viria a se repetir mais de trinta anos depois com o processo que levou este último à prisão.

Em 1854, William-pai mantinha um caso extraconjugal com uma de suas pacientes, a jovem Mary Travers. Quando a relação passou a comprometer profissionalmente o futuro "Sir" William, este tratou de se livrar da moça oferecendo uma viagem à Austrália. Bastante ofendida, Mary Travers adotou o pseudônimo literário "Speranza", pertencente à esposa do amante, Jane Francesca Elgee, e escreveu um panfleto intitulado "Dr and Mrs Quilp" em que narrava a história de uma jovem que era entorpecida com clorofórmio por seu médico e por ele desvirginada. Passados dez anos, a então Lady Wilde, aparentemente certa da inocência do marido, escreve para o pai de Mary Travers informando "que a torrente de calúnias que sua filha esforçava-se em despejar sobre eles era tão somente o produto ignominioso de 'monstruosas maquinações' sintomáticas de uma mulher frustrada” (SCHIFFER, 2010, p. 16). O que, ao tomar conhecimento da referida carta, Mary acusa Lady Wilde na justiça por difamação. Por ter sido recém nomeado "Sir" por Sua Majestade, Lady Wilde conseguiu inocentar o marido, mas este, não resistindo à desonra sofrida, veio a falecer apenas três anos após o processo.

Talvez seja esse o motivo de Wilde tratar sempre sobre a falência da instituição do casamento, especialmente em suas peças, mas culminando em $O$ retrato.

- De nenhuma forma - respondeu lorde Henry, pousando a mão no ombro do amigo. Nem um pouco, meu caro Basil. Você parece esquecer que sou um homem casado, e o único encanto do casamento é que as duas partes são obrigadas a viver uma vida de embustes. (WILDE, 2013, p. 81) 
Além de em $O$ retrato de Dorian Gray Oscar Wilde expor a falência da instituição do casamento, em suas peças teatrais aponta para os diversos componentes do seu álbum de família.

$\mathrm{Na}$ peça "Uma Mulher sem Importância", Wilde traça um panorama da sociedade hipócrita vitoriana da Inglaterra do final do século, quando Lady Carolina Pontefract, um pouco depois de haver criticado - em sua ausência - Lady Hunstanton, a dona da casa, por se mostrar esta "por vezes um tanto indulgente na escolha dos seus convidados" (WILDE, 2007, p. 659), mais adiante põe sobre si a máscara da falsidade, quando se dirige à mesma Lady (Joana) Hunstanton - agora presente.

"L. Car. Consideramos isto muito pouco aconselhável. Joana, estava agora mesmo dizendo que tinhas organizado a mais agradável reunião do mundo. Tens uma aptidão maravilhosa para escolher. É um verdadeiro dom" (WILDE, 2007, p. 660).

Wilde narra a história da Sra. Arbuthnot, uma suposta viúva, mãe de Geraldo Arbuthnot, "uma mulher sem importância", mulher que na juventude se envolveu com Lorde Illingworth tendo se tornado mãe solteira, o que seria uma das maiores humilhações para uma mulher na época. Para proteger o filho, se disfarça de viúva, mas os fios do destino fazem o jovem Geraldo cair nas graças do próprio pai que não sabe ser seu filho.

Além da dura crítica à sociedade que condena a mulher por ter um filho fora do casamento, mas concede ao homem a impunidade, Wilde aponta para a própria vida e a própria obra. Vejamos.

1) Lady Suttfield e a Sra. Allonby no segundo ato apontam para a próxima peça de Wilde, "Um Marido Ideal".

L. Stut. Sim, o senso comum dos maridos é realmente muito fastidioso, fastidiosíssimo. Diga-me qual é a sua concepção do Marido Ideal. Creio que seria muito útil, utilíssima.

$\mathrm{Sr}^{\mathrm{a}}$ Allon. O Marido Ideal? Não pode existir semelhante coisa. A instituição é disparatada.

L. Stut. O Marido Ideal, então, em suas relações para conosco. (WILDE, 2007, p. 675)

2) Lorde Illingworth narra a - sufocante - influência que o próprio Oscar Wilde sofria de sua mãe. 
"L. Ill. Oh! O dever é o que se exige dos outros e não aquilo que a gente mesmo faz. Fui, sem dúvida, influenciado por minha mãe. Todo homem o é, quando jovem" (WILDE, 2007, p. 675).

3) E novamente a condenação explícita à instituição do casamento, semelhante a em $O$ retrato de Dorian Gray.

"L. Ill. Os homens se casam por cansaço; as mulheres por curiosidade. Uns e outros acabam desapontados." (WILDE, 2007, p. 689)

\section{3) O eterno retorno: Jane Frances Elgee \& Oscar Wilde}

Para melhor entender a repetição do que aconteceu com seu pai, Sir William, no processo que levou Oscar Wilde para o Cárcere de Reading, façamos um resumo dos acontecimentos. Em 1882, Oscar Wilde estava no início de sua fama. Após uma trajetória brilhante em Oxford, o jovem Oscar, com apenas 28 anos, havia impresso uma imagem de dândi, com vestimentas, performances e estilo de vida extravagantes, o que rendeu um convite do promotor de espetáculos culturais D'Orly Carte para uma turnê de conferências nos Estados Unidos sobre esteticismo. Foi nessa época que Wilde conheceu Joseph Marshall Stoddart, escritor da Filadélfia, que, sete anos mais tarde, encomendaria ao escritor irlandês radicado na Inglaterra uma "obra original" a ser publicada no jornal de que era proprietário, o Lippincott's Monthly Magazine. Wilde entregou o manuscrito datilografado a Stoddart que, receoso de uma repercussão negativa na sociedade londrina preconceituosa do final do século XIX, resolveu retirar vários trechos do romance - chegando à supressão de mais de quinhentas palavras com conotação homossexual. Em 1891, Wilde revisou e ampliou o texto de treze para vinte capítulos, tendo o cuidado de (tentar) realçar os valores morais e o quase arrependimento de Dorian ao final do livro, publicando-o pela editora inglesa Ward, Lock and Company.

Vale abrir um parêntese no que concerne ao preconceito da sociedade londrina um pouco antes da época do processo de Wilde. Havia acontecido dois escândalos: um com meninas brancas que estavam sendo escravizadas-corrompidas-prostituídas em Londres, o que gerou a Emenda à Lei Criminal de 1885. A Emenda Labouchère (devido ao deputado radical Henry Labouchère) foi acrescida de última hora, e criminalizava "a flagrante indecência" entre homens, o que tornou as práticas homossexuais cada vez mais clandestinas, gerando chantagens entre os prostitutos e clientes. Na época de $O$ retrato, surgiu um boato de que membros da aristocracia estavam envolvidos com rapazes prostitutos, o que deixou a sociedade londrina à flor da pele quanto ao tema da homossexualidade. 
$O$ retrato de Dorian Gray narra a história do belo e jovem Dorian (do grego "dórico", referente à tradição nos gregos antigos de um homem mais velho manter um jovem como amante) cujo retrato é pintado por Basil Hallward, e influenciado pelo hedonista Lorde Henry Wotton. Na versão que entregou a Stoddart, Wilde deixava bem explícito a homossexualidade implícita do pintor Basil e a paixão avassaladora que este sentiu por Dorian desde o primeiro encontro. Tomemos o seguinte exemplo quando Basil fala com Dorian:

Admito que o adorei loucamente, extravagantemente, absurdamente. (A) Tinha ciúme de qualquer pessoa com quem você falasse. Queria tê-lo todo só para mim. Só me sentia feliz quando estava com você. Quando nos separávamos, você continuava presente em minha arte. Era tudo errado e tolo. Ainda é tudo errado e tolo. (B) Obviamente, nunca deixei você saber nada sobre isso. Teria sido impossível. Você não teria entendido, eu mesmo não entendia. Certo dia decidi pintar seu maravilhoso retrato. Era para ser minha obra-prima. Mas, à medida que trabalhava, cada pincelada e cada camada de cor pareciam revelar meu segredo. Havia amor em cada traço, em cada toque havia paixão. (C) (WILDE, 2013, p. 206-207)

Os trechos (A) e (B) acima marcados foram substituídos ou mesmo excluídos por Oscar Wilde. Na edição de 1891, o trecho (A) foi substituído de "Admito que o adorei loucamente, extravagantemente, absurdamente" por "Minha alma, meu cérebro, minha força de vontade foram dominadas por você. Você se tornou para mim a encarnação daquele ideal invisível cuja memória persegue os artistas como um sonho estranho. Eu o idolatrei". O trecho (B), "Era tudo errado e tolo. Ainda é tudo errado e tolo" foi completamente eliminado em 1891. Mas o trecho (C) "Havia amor em cada traço, em cada toque havia paixão" foi totalmente eliminado por Stoddart na edição da Lippincott's em 1890, aparentemente sem nenhuma consulta e autorização do autor.

Apesar dos cortes e alterações efetuados por Stoddart e as futuras modificações de Wilde para a publicação em livro, o fato é que o texto que saiu na edição de julho de 1890 da Lippincott's foi amplamente utilizado pelo advogado do Marquês de Queensberry, Edward Carson, ao acusar Oscar Wilde de sodomia e má influência ao jovem Lorde Alfred Douglas, filho de seu cliente.

Gostaríamos de analisar essa repetição de processos: 1) a reversão no processo de Lady Wilde contra Mary Travers conseguindo inocentar Sir William Wilde; 2) a defesa de Lady Wilde do seu editor Charles Gavan Duffy quanto à autoria dos artigos panfletários na The Nation conseguindo libertá-lo da prisão; 3) a reversão no processo de Oscar Wilde contra o pai de Lorde Alfred Douglas referente ao escândalo sexual envolvendo homossexualidade com menores em que o escritor irlandês estava envolvido. 


\title{
4) O Narcisismo Primário e Narcisismo Secundário: Um retrato de Dorian Gray
}

No volume XIV de A história do movimento psicanalítico, Sigmund Freud analisa o aparecimento do conceito de Narcisismo.

\begin{abstract}
Trata-se de um dos mais importantes trabalhos de Freud, podendo ser considerado como um dos fatores centrais na evolução de seus conceitos. Resume suas primeiras discussões sobre o tema do narcisismo e considera o lugar ocupado pelo narcisismo no desenvolvimento sexual, indo, porém, além disso, pois penetra nos problemas mais profundos das relações entre "libido do ego" e "libido objetal". (STRACHEY in FREUD, 1974, p. 86)
\end{abstract}

Freud explica que todo o ser humano, portador ou não de neurose, passa pela fase de narcisismo primário na sua constituição psíquica. Do narcisismo primário na criança onipotente, em que o mundo é perfeito e gira ao seu redor, o indivíduo passa da libido do ego para a libido objetal, normalmente quando se apaixona. Essa volta à plenitude infantil de amar e ser amado é chamado de narcisismo secundário. Se uma falha ocorre no processo de saída da libido do ego para a libido objetal, o retorno ao ego é feito de maneira fraturada, retrocedendo a um narcisismo primário e aí paralisando.

O termo narcisismo vem do mito grego de Narciso (BITTENCOURT, 2009, p. 68-71). Uma das versões do mito encontra-se em As metamorfoses (Livro III, 339-510, 756-762 d.C), de Ovídio, que narra a história de Narciso, jovem de extraordinária beleza que atraía e recusava pessoas de ambos os sexos. A ninfa Eco, ao ser recusada pelo jovem, fecha-se numa imensa solidão até a morte, e é vingada pela deusa da justiça Nêmesis, que lança a Narciso uma maldição: condena-o a sofrer a mesma paixão não correspondida por um ser inalcançável. Ao chegar a um pequeno lago, Narciso vê sua própria imagem refletida na água e se apaixona perdidamente. Incapaz de possuir a própria imagem, definha e morre de tristeza.

À luz dos conceitos de Freud, analisaremos nesse estudo dois pontos. O primeiro é o que ocorre em Oscar Wilde na relação afetiva com sua mãe: a regressão ao narcisismo primário na infância que paralisa o filho e, no momento em que Lady Wilde o chantageia, mesmo ciente da proximidade da prisão por causa do processo de escândalo sexual, o impede de fugir.

A partir da relação fusional com a mãe, a qual se realizava literariamente no filho, e, ao mesmo tempo, no momento crucial em que o pai cortaria a relação simbiótica entre mãe e filho, ou seja, em torno dos dez aos doze anos, ocorre o escândalo sexual de Sir William com Mary Travers, o que impede Oscar Wilde de admirar esse pai, e sair do espelho paralisante do narcisismo primário. Com filho e mãe unos, sem a presença desse pai, Narciso/Oscar vê a mãe como uma continuação de seu 
próprio corpo, não sendo a imagem dela por quem se apaixona, mas a sua própria imagem refletida nas águas do lago.

Dorian não respondeu, mas passou letargicamente diante do quadro antes de se voltar para observá-lo. Quando o viu, recuou, o rosto ruborizado pelo prazer. Seus olhos se encheram de alegria, como se pela primeira vez houvesse reconhecido a si próprio. Lá ficou, imóvel e pasmo, vagamente consciente de que Hallward falava com ele, mas sem compreender o sentido das palavras. A consciência de sua própria beleza veio como uma revelação. (WILDE, 2013, p. 116)

Apesar de seu lema de que a arte é superior ao real, e que o "objetivo da arte é se revelar enquanto esconde o artista" (WILDE, 2013, p. 324), Wilde reflete essa vida inteiramente na sua obra, derrama-se na sua arte, em especial em $O$ retrato de Dorian Gray. Em certa ocasião chega mesmo a admitir que o livro "contém muito de mim. Basil Hallward é quem eu penso que sou; lorde Henry o que o mundo pensa que eu sou; e Dorian Gray o que eu gostaria de ser - em outras eras, talvez" (WILDE, 2013, p. 2223).

Wilde caminha e constrói o seu caminho no exato instante em que o trilha. Seguindo uma linha condutora muito semelhante com a que seu pai viveu, repete o que já foi vivido e não consegue fugir de seu destino. Na escrita, na publicação da Lippincott's, e na publicação do livro ampliado, mesmo com todas as revisões, expurgações, reorientações da estória para haver um fundo de moral em Dorian, mesmo assim, Oscar Wilde parece buscar e repetir o fado de seu pai, Sir William.

\section{5) Oscar Wilde: Um arruinado pelo êxito?}

No mesmo volume (XIV) de A história do movimento psicanalítico, Freud analisa em "Os arruinados pelo êxito" os casos em que as pessoas adoecem, paralisam e até mesmo morrem no momento do êxito, no instante da felicidade.

O trabalho psicanalítico proporcionou-nos a tese segundo a qual as pessoas adoecem de neurose como resultado de frustração. Referimo-nos à frustração da satisfação de seus desejos libidinais, fazendo-nos necessária uma digressão a fim de tornarmos a tese inteligível. Para que uma neurose seja gerada deve haver um conflito entre os desejos libidinais de uma pessoa e a parte de sua personalidade que denominamos de ego, que é a expressão do seu instinto de autopreservação e que também abrange os ideais de sua personalidade.

(...)

Parece ainda mais surpreendente, e na realidade atordoante, quando, na qualidade de médico, se faz a descoberta de que as pessoas ocasionalmente adoecem precisamente no momento em que o desejo profundamente enraizado e de há muito alimentado atinge a 
realização. Então, é como se elas não fossem capazes de tolerar sua felicidade, pois não pode haver dúvida de que existe uma ligação causal entre seu êxito e o fato de adoecerem. (FREUD, 1974, p. 357)

A partir da narração de dois textos ficcionais, Macbeth, de William Shakespeare, e Rosmersholm, de Henrik Ibsen, Freud irá analisar o comportamento das duas personagens centrais, respectivamente, Lady Macbeth e Rebecca Gamvik. Durante a análise dos textos, ele irá expor e nos questionar do porquê de Lady Macbeth, apesar de vitoriosa, de ter conseguido assassinar quem lhe impediria de tornar-se rainha, inicia uma sequência de episódios de sonambulismo e repetições compulsivas - vide a cena da interminável lavagem das mãos para tentar limpar o sangue das vítimas. Da mesma forma, Rebecca Gamvik quando está prestes a tornar-se a esposa de seu patrão Johannes Rosmer, é tomada por uma impotência paralisante, que não tem a ver com a culpa por induzir o suicídio da esposa doente de Rosmer, mas por causa de um segredo de seu passado que não consegue identificar e decifrar, e que a lança no "caminhar cegamente" ao encontro de seu destino. Quando o irmão da esposa de Rosmer, o Prior Kroll, revela que Rebecca era filha de Dr. West que a adotou e com quem, sem saber que era filha, manteve relações sexuais, o véu da cegueira se desfaz, e Rebecca entende porque não pôde ser feliz no êxito com Rosmer: ela simplesmente estaria repetindo conscientemente o que viveu inconscientemente com seu pai.

Freud considera que esta força poderosa que atua nessas personagens (símbolos de seres humanos reais e transformados através da arte) é proveniente do complexo de Édipo mal elaborado.

O trabalho psicanalítico nos ensina que as forças da consciência que induzem à doença, em consequência do êxito, em vez de, como normalmente, em consequência da frustração, se acham intimamente relacionadas com o complexo de Édipo, a relação com o pai e a mãe - como talvez, na realidade, se ache o nosso sentimento de culpa em geral. (FREUD, 1974, p. 374)

O mito de Édipo narra a história do filho do rei e da rainha de Tebas, Laio e Jocasta, que, para fugir da profecia do oráculo de Delfos de que iria matar seu pai e casar com sua mãe, abandona os pais, que não sabe serem adotivos, e acaba indo ao encontro de seus verdadeiros pais, ou seja, cumprir a profecia do oráculo.

Voltemos à cena inicial de nosso estudo, quando Oscar Wilde, no quarto do Cadogan Hotel, a poucas horas de ser preso, incentivado por seus amigos a fugir, se entregou e paralisou diante dos apelos possessivos de sua mãe, mulher que por duas vezes havia livrado homens das garras da justiça, Sir William e Charles Duffy, e agora acreditava que o livramento iria se repetir com seu filho predileto. 
Wilde agia de forma inconsciente em seu processo, a começar por não revelar a verdade a seus advogados, quando não assumiu sua homossexualidade, sua relação amorosa com Lorde Alfred Douglas, a frequentação clandestina de bordéis e rapazes prostitutos. Na escrita da primeira versão de $O$ retrato de Dorian Gray, deixa escapar frases que o acusarão mais adiante no processo, inclusive sendo utilizadas contra ele como prova de sua sodomia pelo advogado Edward Carson.

\begin{abstract}
Impressionado com essa ideia do "prazer mais trágico" que Oscar não parava de reivindicar, [André] Gide acrescentava que esse mesmo Wilde, consciente dessa "fatalidade que o conduzia" e colocando "todo o seu cuidado, sua virtude, a se exagerar o destino", disse que, longe de se ater à prudência que seus amigos lhe aconselhavam, pretendia ao contrário não mais "voltar atrás". E, levando a provocação ao extremo, queria ir "tão longe quanto possível", até que "Acontecesse alguma coisa... alguma outra coisa..." (SCHIFFER, 2009, p. 197-198, colchetes nossos)
\end{abstract}

Se por um lado essa "alguma coisa... alguma outra coisa" que impelia Oscar Wilde a essa queda no abismo, a repetir o destino trágico de seu pai, que, apesar de inocentado no processo de estrupo de Mary Travers, adoece e morre numa questão de três anos, por outro lado, Lady Wilde/mãe/Jocasta, ao pedir que permanecesse em Londres para ser preso, estava reforçando a "queda no abismo" de Oscar/filho/Édipo, a entrega inexorável ao destino que inconscientemente desejara para o marido traidor Sir William/pai/Laio, ou seja, a expiação da culpa do escândalo sexual do pai que foi inocentado na condenação pelo escândalo sexual do filho.

O que realmente desejava dizer Lady Wilde com o seu pedido, com a sua fala?

Deleuze propõe mudar radicalmente o questionamento acerca dos objetos. A tradição platônica inquere: “o que é?"; a partir de Nietzsche sugere-se: "o que quer?". Pois essa é a ordem da nossa investigação: o que se quer ao dizer? Diferente das tradições hermenêuticas que interrogam: "o que quer dizer?", presumindo que haverá algum intérprete privilegiado, essa resposta investigativa é: "o que se quer ao dizer", afinal, "uma palavra só quer dizer qualquer coisa à medida que aquele que diz quer qualquer coisa ao dizê-lo. E só uma regra: tratar a fala como uma atividade real, colocar-se no ponto de vista daquele que fala". (DELEUZE in MONTEIRO, 2011, p. 154-155)

Notemos que essa paralisia em Wilde encontra-se tanto em sua vida quanto em sua arte. Em $O$ retrato, Dorian Gray não consegue se livrar da consciência-quadro quando supõe estar fazendo o bem ao se afastar da jovem Hetty Merton para não prejudicá-la. 
Seria realmente verdade que ninguém era capaz de mudar? Sentiu uma saudade imensa da pureza intocada de sua meninice - a meninice branca e cor-de-rosa, como lorde Henry certa vez a definira. Sabia que havia se maculado, enchido a mente com degradações e tingido de horror seus devaneios; que tinha exercido uma má influência sobre outros, e sentido terrível prazer em fazê-lo. E, das vidas que haviam cruzado com a sua, ele havia desgraçado as mais límpidas e mais promissoras. Mas seria tudo isso irremediável? Não havia nenhuma esperança para ele? (WILDE, 2013, p. 307)

E feito um Édipo que cega os próprios olhos por não ter antes enxergado a sua sina, Wilde, apesar de todo o sofrimento registrado e expurgado na longa cartaconsciência, "De Profundis", quando no Cárcere de Reading por causa de seu relacionamento amoroso com Lorde Alfred Douglas, o Bosie, é exatamente ao Bosie que retorna na primeira oportunidade ao sair da prisão, feito para realizar o último ato da tragédia de Sófocles.

Curiosamente, feito profetizasse os futuros acontecimentos (ou mesmo buscasse por eles), Wilde escreve o seu mais longo poema "A Esfinge" (1894). Édipo, para conquistar Tebas e a futura esposa, a rainha Jocasta (que não sabe ser sua mãe), desvenda o segredo da Esfinge.

- "Qual é o animal que tem quatro patas de manhã, duas ao meio dia e três à noite?

No que Édipo responde:

- O homem. O amanhecer é a criança engatinhando, o entardecer é a fase adulta, que usamos ambas as pernas, e o anoitecer é a velhice que usa a bengala."

Ao responder o enigma da Esfinge abocanhadora, Édipo não enxerga que esse homem era si mesmo: o indagado, o "decifrador". Oscar Wilde, ao assumir o lugar do pai atendendo ao pedido da mãe-Esfinge de não fugir, é condenado e passa a ser o Édipo/marido da mãe, paralisado, arruinado pelo êxito.

False Sphinx! False Sphinx! By reedy Styx old Charon, leaning on his oar,

Waits for my coin. Go thou before, and leave me to my crucifix,

Whose pallid burden, sick with pain, watches the world with wearied eyes,

And weeps for every soul that dies, and weeps for every soul in vain. (WILDE, 1993, p. 821)

Esfinge falaz! Esfinge falaz! Pelo débil Styx, velho Charon, apoiado em seu remo,

Espera por meu castigo. Partes tu antes, e deixa-me com meu crucifixo, 
De quem pálido fardo, doente com dor, observas o mundo com olhos fatigados,

E choras por cada alma que morre, e choras por cada alma em vão. (WILDE, 1993, p. 821 , tradução nossa)

\section{6) Quando tudo se repete: De volta à conclusão}

Ao finalizar esse breve estudo "Jane Frances Elgee \& Oscar Wilde: Uma Teoria dos Afetos”, resta lançar uma última pergunta/hipótese a (tentar) ser desvendada/aprofundada futuramente:

- Existe alguma relação entre a falha na passagem do narcisismo primário para o narcisismo secundário, gerando a regressão da libido objetal à libido do ego com a determinação paralisante e arruinadora do complexo de Édipo? No caso de Oscar Wilde, existe alguma relação do trauma ocorrido aos dez anos com o escândalo sexual do pai, com a regressão à paralisia do narcisismo primário, propiciando que no quarto do Cadogan Hotel não tenha conseguido fugir atendendo ao pedido da mãe, e assim cumprindo o destino edipiano de matar (castigar) o pai e se casar com a (assumir o lugar do marido da) mãe?

\section{Referências Bibliográficas}

BITTENCOURT, Frederico Luis Domingues. Ecos de Narciso [manuscrito]: leitura do livro Ecos, de Yêda Schmaltz. Dissertação (Mestrado) - Universidade Federal de Goiás, Faculdade de Letras, 2009. Disponível no http://pos.letras.ufg.br/uploads/26/original_dissert_frederico_compl.pdf. Última consulta em 06/07/2014.

FREUD, Sigmund. A história do movimento psicanalítico. Volume XIV. Comentários e notas: James Strachey. Tradução sob Direção-Geral e Revisão Técnica: Jayme Salomão. Rio de Janeiro: Imago, 1974.

JUNIOR, Aristides Jose da Silva, MONTEIRO, Silas Borges et MORAES, Maria Auxiliadora Maciel de. Otobiografia: a escuta das vivências como escolha teóricametodológica para pesquisa em educação e saúde. 16 $6^{\circ}$ SENPE. Campo Grande, MS, 2011. 
LEJEUNE, Philippe. O pacto autobiográfico: De Rousseau à Internet. Organização Jovita Gerheim Noronha. Tradução: Jovita Maria Gerheim Noronha e Maria Inês Coimbra Guedes. Belo Horizonte: Editora UFMG, 2008.

SCHIFFER, Daniel Salvatore. Oscar Wilde. Tradução: Joana Canêdo. Porto Alegre, RS: L\&PM, 2010.

SÓFOCLES. Rei Édipo. Introdução, tradução e notas: Ordep Serra. $2^{\mathrm{a}}$ ed. São Paulo: Martin Claret, 2010.

. Édipo Rei. Tradução: Paulo Neves. Porto Alegre: L\&PM, 2014.

WILDE, Oscar. De Profundis e outros escritos do cárcere. Tradução: Júlia Tettamanzy. Porto Alegre: L\&PM, 2006.

The Complete Plays, Poems, Novels and Stories of Oscar Wilde. London, England: Magpie Books/Robinson Publishing, 1993.

. Vera ou os Niilistas. Obra completa. Volume único. Introdução geral e Nota editorial, Ensaio Biográfico-Crítico, Bibliografia, Cronologia da Vida e da Obra: James Laver. Tradução: Oscar Mendes. Rio de Janeiro: Nova Aguilar, 2007, p. 455-499.

A Duquesa de Pádua. Obra completa. Volume único. Introdução geral e Nota editorial, Ensaio Biográfico-Crítico, Bibliografia, Cronologia da Vida e da Obra: James Laver. Tradução: Oscar Mendes. Rio de Janeiro: Nova Aguilar, 2007, p. 505-558.

A Importância de ser Prudente. Obra completa. Volume único. Introdução geral e Nota editorial, Ensaio Biográfico-Crítico, Bibliografia, Cronologia da Vida e da Obra: James Laver. Tradução: Oscar Mendes. Rio de Janeiro: Nova Aguilar, 2007, p. 791-840.

O Leque de Lady Windermere. Obra completa. Volume único. Introdução geral e Nota editorial, Ensaio Biográfico-Crítico, Bibliografia, Cronologia da Vida e da Obra: James Laver. Tradução: Oscar Mendes. Rio de Janeiro: Nova Aguilar, 2007, p. 563-608.

- Uma Mulher sem Importância. Obra completa. Volume único. Introdução geral e Nota editorial, Ensaio Biográfico-Crítico, Bibliografia, Cronologia da Vida e da Obra: James Laver. Tradução: Oscar Mendes. Rio de Janeiro: Nova Aguilar, 2007, p. 659-610.

O retrato de Dorian Gray. Tradução: Lígia Junqueira. Rio de Janeiro: Civilização Brasileira, 2007.

Organização: Nicholas Frankel. Tradução:

Jorio Dauster. Ed. anotada e não censurada. São Paulo: Globo, 2013. - (Biblioteca Azul). 